\title{
Rectal Duplication Cyst Mimicking Rectal Prolapse
}

Open Access

\author{
Asrar Ahmad, Eelaf Karar, Irum Saleem, Nisar Ahmad
}

\begin{abstract}
:
Gastrointestinal tract duplications are rare congenital malformations that are benign, presenting usually in childhood. Most common sites include the distal ileum and oesophagus. Rectal presentation is quite uncommon and is usually cystic. This is a case of a three year old boy who came with rectal prolapse. On further examination and imaging investigations a presacral cyst was located and a diagnosis of rectal duplication was made. The cyst was completely excised by a posterior sagittal approach.
\end{abstract}

Keywords: Gangrene, Ileostom, laparatomy, volvulus.

How to cite this Article:

Ahmed A, Karar E, Saleem U, Ahmed N. Rectal Duplication Cyst Mimicking Rectal Prolapse. J Bahria Uni Med Dental Coll. 2021; 11(1):44-45 DOI: https://doi.org/10.51985/ZHCU2343

This is an Open Access article distributed under the terms of the Creative Commons Attriution Non Commercial Liciense (http:// creativecommons/org/licences/by-nc/4.0) which permits unrestricted non commercial use, distribution and reproduction in any medium, provided the original work is properly cited.

INTRODUCTION:

The incidence of gastrointestinal duplication cysts is 1 in 10,000 live births and hence it is quite a rare congenital abnormality. Rectal duplications represent $5 \%$ of all duplications in the alimentary tract. ${ }^{1}$ Most rectal duplications are cystic (94\%) and are usually recognized as perianal abscesses, fistulas or tumours. ${ }^{2}$ Knudtson $\mathrm{et}_{\mathrm{al}} \mathrm{l}^{3}$ assess that up to $45 \%$ of rectal duplications are associated with a fistula to the anus or perianal region. ${ }^{3}$ Tubular duplications of the rectum are generally located posteriorly and have been anterior to the rectum in only a few reported cases. ${ }^{4}$ Most patients present with constipation, rectal bleeding, urinary tract infection, rectal prolapse, haemorrhoids and perirectal abscess. Diagnosis starts with ultrasound examination, plain radiography of the abdomen, contrast enema, computed tomography and MRI study. ${ }^{5}$

\section{CASE REPORT:}

In December 2017 a three years old male child was referred from a peripheral hospital to Combined Military Hospital Nowshera, where he had undergone examination under anaesthesia (EUA). The mother complained of something coming out of anus on defecation for the last four months. The mass would at times reduce spontaneously and at times

Г - - - - - - - - - - - - -

I Asrar Ahmad

PNS Shifa Hospitatric Surgeon,

Karachi

E-mail: drasrar.ahmad@yahoo.com

I Eelaf Karar

Medical Officer,

I PNS Shifa Hospital, Karachi

I

Irum Saleem

Registrar, Department of Gynaecology

I Bahria University Medical Dental College, Karachi

I Nisar Ahmad

I Medical Officer,

Hayatabad Medical Complex, Peshawar

I Received: 03-Jul-2020

Accepted: 07-Oct-2020

Accepted. 07-Oct-2020 would cause pain and had to be reduced manually. Moreover, it will not comprise the whole circumference of the anus. There was no history of constipation, diarrhoea or bleeding per rectum. On EUA they found a large bulging mass in the posterior wall of the rectum. On digital rectal examination a cystic mass was palpable in the posterior wall of the rectum. The upper limit could be reached. The overlying rectal mucosa was normal. No communication with the rectum was visible. His complete blood counts, serum electrolytes and renal function tests were normal. Ultrasound pelvis was suggestive of a cystic lesion in the presacral space. CT scan pelvis was suggestive of a well-defined round to oval shaped, non-enhancing, cystic mass lesion in presacral region measuring about $3.7 \times 3.3 \times 3.5 \mathrm{~cm}$. It was compressing the rectum antero-laterally with indistinct interface. The interface with sacrum was intact and there was no erosion of bone. A diagnosis of rectal duplication cyst was made (Figure.1). He was prepared for surgery. Gut preparation was done. The cyst was approached through posterior sagittal incision. The muscularis propria of rectum was opened and the cyst was excised completely without opening the mucosa of rectum (Figure.2). The muscularis propria was repaired with absorbable interrupted sutures and skin wound closure done with subcuticular suture. He made a smooth post-operative recovery and was discharged on the $4^{\text {th }}$ post-operative day. The patient recovered completely and follow up revealed no complaints. A signed informed consent was obtained from the guardian of the child for writing and publishing this case report.

\section{DISCUSSION:}

Gastrointestinal (GI) duplications are a very uncommon but complex set of embryological disorders that can involve any part of the alimentary canal from the tongue to the anus. Duplications of any kind share common characteristics like, they are hollow, lined with gastrointestinal tract epithelium and have a smooth muscle wall. Gastrointestinal duplications were initially believed to be more come in males but it was later confirmed that there is an equal male to female ratio. ${ }^{6}$ 
Figure.1 CECT Scan of abdomen showing pre-sacral cystic mass

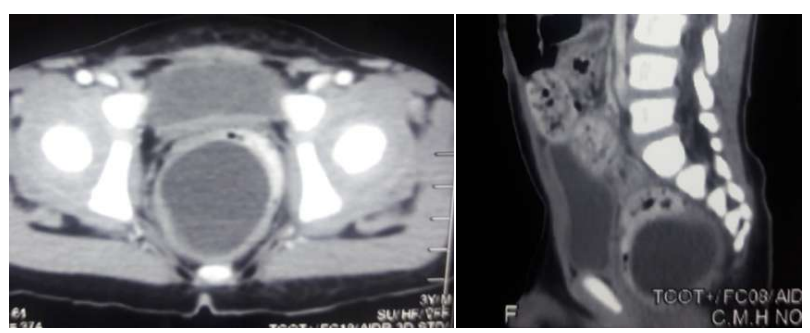

Figure.2 Rectal duplication cyst from a posterior sagittal approach

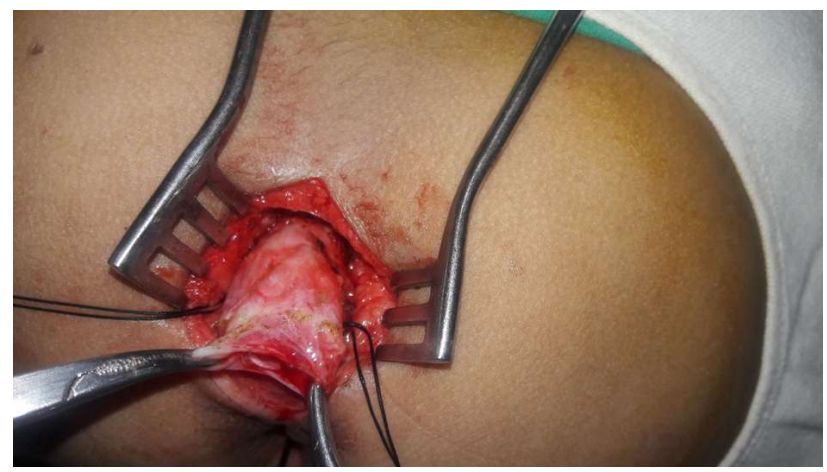

Colonic duplications account for $15 \%$ and rectal duplications account for $5 \%$ of all alimentary canal duplications. ${ }^{7,1}$ The exact pathogenesis of duplications is unknown and multiple theories have been put forward. According to the most credible theory, as the rapidly growing endothelial cells occlude the intestinal lumen, vacuoles form inside the cell masses due to the growth of the intestine. These vacuoles fuse to create a single lumen intestine. If one of these vacuoles pinches off, they can create a secondary lumen, which may entirely be separated from the main lumen but grows in proportion to the main lumen. Colonic duplications can be cystic or tubular involving a limited portion of the colon or be extensive. They are usually divided into two types, type I and II. Type I usually has partial involvement of the colon or rectum while type II has a wider spectrum as in addition to colon and rectum, there can also be associated congenital anomalies including duplication of the lower genitourinary tract, double appendices, situs inversus and neural tube defects. Ultrasonography and contrast studies are most widely used. Computed tomography (CT) and magnetic resonance imaging (MRI), although less often used, are helpful in localizing and diagnosing complex duplications. ${ }^{8}$ Rectal Duplications are treated with complete surgical excision of the cyst by transanal, transcoccigeal or posterior saggital approach. Other less invasive ways include transanal endoscopic microsurgery or transabdominal laproscopic surgery. ${ }^{9}$ These duplication may mimic a tail gut cyst, anterior sacral menengocele, cystic sacrococcygeal teratoma, anal duct or gland cyst, necrotic rectal leiomyosarcoma, dermoid cyst, epidermoid cyst, cystic lymphangioma, neuroenteric cyst and necrotic sacral chordoma. ${ }^{10}$
Tail gut cysts are usually multilocular and present later in life. Epidermoid cysts are thin walled filled with clear fluid.

Dermoids are heterogenous with skin appendages. Sacrococcygeal teratomas are also heterogenous lesions with mixed cystic and solid components. Anterial sacral meningocele and neuroenteric cysts are better differentiated with MRI because of its communication with the subarachnoid space.

\section{CONCLUSION:}

Although rare, gastrointestinal tract duplications can present by various ways and have to be ruled out in case of suspicion by good imaging modalities and then be treated with complete surgical excision by a favourable approach to relieve symptoms and prevent complications.

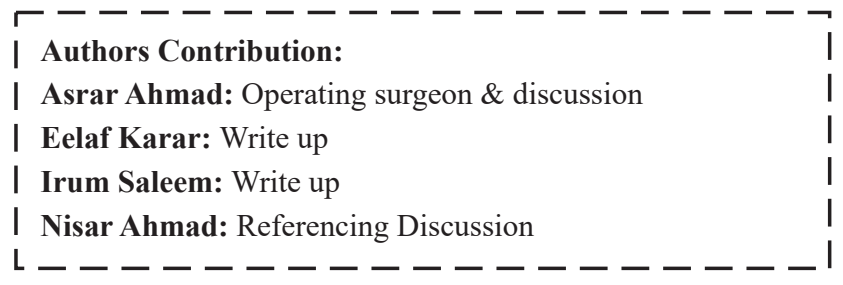

REFERENCE:

1. Rattan KN, Bansal S, Dhamija A. Gastrointestinal duplication presenting as neonatal intestinal obstruction: an experience of 15 years at tertiary care centre. Journal of neonatal surgery. 2017 Jan;6(1).

2. Lu T, Zhao G, Wang K, et al. An unusual case of tubular rectal duplication mimicking teratoma recurrence and review of the literature. Eur J Radiol Extra 2010; 73: e17-9.

3. Kassa HT, Cohen ST, Martin AE, Solaiman AZ. Gastrointestinal duplication cyst resulting in abdominal obstruction, pancreatitis, and intractable vomiting. Journal of Pediatric Surgery Case Reports. 2020 Dec 1;63:101656.

4. Kim JY, Youn JK, Kim SH, Kim HY, Jung SE, Park KW. Anterior Anorectocolonic Tubular Duplication Presenting as Rectovestibular Fistula in an Infant. Journal of the Korean Association of Pediatric Surgeons. 2017 Dec 1;23(2):55-8.

5. Marzena Nosek, Anna Golonka, Anita Kaliñska-Lipert, Pawe ${ }^{3}$ Nachulewicz. Rectal duplication with sciatic hernia. Videosurgery Miniinv 2015; 10 (2): 282-285.

6. Patel H, Watterson C, Chow JS. Case of urethral duplication seen by voiding urosonography. Clinical Imaging. 2018 May 1;49:106-10.

7. Karkera PJ, Bendre P, D'souza F, Ramchandra M, Nage A, Palse N. Tubular colonic duplication presenting as rectovestibular fistula. Pediatric gastroenterology, hepatology \& nutrition. 2015 ;18(3):197-201.

8. Al-Salem AH. Gastrointestinal Duplications. InAtlas of Pediatric Surgery 2020 (pp. 481-484). Springer, Cham.

9. Ceriotti M, Saccomani G, Lacelli F, Saccomani GE. Wide rectal duplication cyst in an adult resected by anterior approach: efficacy and recurrence. Journal of surgical case reports. 2017 ;1(6):rjx115.

10. Xiang L, Lan J, Chen B, Li P, Guo C. Clinical characteristics of gastrointestinal tract duplications in children: A singleinstitution series review. Medicine. 2019 Nov;98(44). 